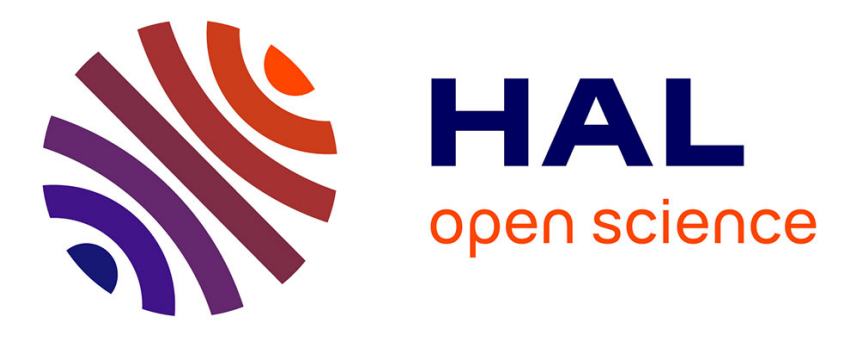

\title{
Sporting activity and drug use: alcohol, cigarette and cannabis use among elite student athletes
}

Patrick Peretti-Watel, Valérie Guagliardo, Pierre Verger, Jacques Pruvost, Patrick Mignon, Yolande Obadia

\section{- To cite this version:}

Patrick Peretti-Watel, Valérie Guagliardo, Pierre Verger, Jacques Pruvost, Patrick Mignon, et al.. Sporting activity and drug use: alcohol, cigarette and cannabis use among elite student athletes. Addiction, 2003, 98, pp.1249-1256. hal-01753448

HAL Id: hal-01753448

https: / hal-insep.archives-ouvertes.fr/hal-01753448

Submitted on 29 Mar 2018

HAL is a multi-disciplinary open access archive for the deposit and dissemination of scientific research documents, whether they are published or not. The documents may come from teaching and research institutions in France or abroad, or from public or private research centers.
L'archive ouverte pluridisciplinaire HAL, est destinée au dépôt et à la diffusion de documents scientifiques de niveau recherche, publiés ou non, émanant des établissements d'enseignement et de recherche français ou étrangers, des laboratoires publics ou privés. 


\title{
Sporting activity and drug use: alcohol, cigarette and cannabis use among elite student athletes
}

\author{
Patrick Peretti-Watel ${ }^{1,2}$, Valérie Guagliardo ${ }^{1,2}$, Pierre Verger ${ }^{1,2}$, Jacques Pruvost ${ }^{3}$, \\ Patrick Mignon ${ }^{4} \&$ Yolande Obadia ${ }^{1,2}$ \\ 'Regional Centre for Disease Control of South-Eastern France (ORS PACA), 'INSERM Research Unit 379, 'Social Sciences Applied to Medical Innovation', \\ Institut Paoli Calmettes, ${ }^{3}$ Regional and Departmental Authority on Youth and Sports of South-Eastern France (DRDJS PACA), Marseille, France and \\ ${ }^{4}$ Laboratory of Sociology of Sport, National Institute for Sport and Physical Education (INSEP), Paris, France
}

Correspondence to:

Patrick Peretti-Watel ORS-PACA INSERM U379

23 rue Stanislas Torrents

13006 Marseille

France

E-mail: peretti@marseille.inserm.fr

\section{ABSTRACT}

Aims To study the relationship between sporting activity and alcohol, cigarette and cannabis use among adolescents and young adults, by focusing on elite student athletes (ESAs).

Design, setting, subjects Cross-sectional survey (Spring 2002), in a sample of 460 ESAs (ages 16-24 years) recruited at 40 public centres gathering the young sporting elite from 30 different sports in South-Eastern France, comparison with samples of the general population of adolescents in South-Eastern France.

Measures Respondents were asked confidentially by a self-administered questionnaire about their use of licit and illicit drugs, their sporting activity and other aspects of their life-style.

Findings Prevalences of cigarette, alcohol and cannabis use were markedly lower for ESAs than for other adolescents (generally twice or threetimes as low). Among ESAs, when compared with the practice of an individual sport, the practice of a team sport was correlated positively with alcohol use ( $\mathrm{OR}=2.7$ for girls, $\mathrm{OR}=1.8$ for boys), and the practice of a sliding sport was correlated positively with cannabis use (for girls: $\mathrm{OR}=2.3$ ) and with alcohol use (for boys: 4.3 ). Girls who entered competition at international level were more prone to smoke cigarettes and cannabis ( $\mathrm{OR}=6.1$ and 2.4 , respectively).

Conclusions As a whole, practising sports as an elite student-athlete can be considered as correlated negatively with cigarette, alcohol and cannabis use. Nevertheless, this relationship depends on the kind of sport practised as well as the level of competition, and further research is needed to understand specific elite athletes' motives for use.

KEYWORDS Drug use, elite student athletes, sport.

\section{INTRODUCTION}

The scientific literature on the drug-sport relationship has expanded rapidly during the last decade: a search on Medline in November 2002 with 'drug use' and 'sport' resulted in 51 hits before 1980, 76 for the 1980s, 222 for the 1990 s and already 69 from 2000 to 2002. Most of these papers deal with doping, but an increasing number are focused on recreational drug use, especially cigarette, alcohol and cannabis use in adolescents. This growing interest is connected with a new concern about possible adverse consequences of sporting activity, which is suspected to increase risks of drug use. Recently, several surveys focusing on adolescents from different developed countries suggested that sports participation could be considered as protective against drinking alcohol, cigarette smoking or illegal drug use (McArdle et al. 2000; Pate et al. 2000; Naylor, Gardner \& Zaichowsky 2001; Hellandsjo-Bu et al. 2002). Other surveys led to more qualified conclusions: the drug-sport link atadolescence 
would depend on which sport activities are measured (Challier et al. 2000) and which drug uses are considered (Wechsler et al. 1997), but would also vary with gender (Kokotailo et al. 1996). More generally, this link appears to be a rather complex one: its analysis needs to take into account many parameters (including the type of sport practised, the level of competition and the context of practice) and to control confounding factors, especially age and gender (Choquet \& Arvers 2002; Lorente 2002; Peretti-Watel, Beck \& Legleye 2002).

One way to understand better the drug-sport link is to design specific surveys focusing on athletes with an homogeneous sporting background, but such surveys generally did not deal with elite athletes (for alcohol: Forman et al. 1995; Quarrie et al. 1996; Thombs 2000; for tobacco: Rolandsson \& Hugoson 2000; Walsh et al. 2000; for licit and illicit drugs: Green et al. 2001) or were confined to very small samples (for example: Bower \& Martin 1999). We present here the results of a cross-sectional survey focusing on elite student athletes (ESAs) carried out in South-Eastern France. This survey gave us the opportunity to address current issues concerning the relationships between drug use and sporting activity (type of sport, duration of practice, competitive level) among adolescents and young adults who are committed strongly to sport. Moreover, as national databases with large regional subsamples were available, we also compared ESAs with other adolescents and young adults living in the same area.

\section{METHOD}

\section{Data source}

The data presented in this study were abstracted from the Survey on Elite Provençal Student athletes (SEPSA) conducted by the Regional Centre for Disease Control of South-Eastern France (ORS-PACA), in partnership with the Regional and Departmental Authority on Youth and Sports and the Sport and Physical Education National Institute. Each year, the French sports federations draw up a list of the best young athletes and propose them to enter specialized public centres administered at regional level. These centres organize athletes' training programmes, school timetables and medical follow-up. The SEPSA survey targeted ESAs aged 16-24 years and registered in the centres located in South-Eastern France (i.e. Provence, the Alps and the French Riviera), which is placed third among French regions for ESAs numbers, with 45 centres gathering about 1000 ESAs. Among these 45 centres, five were not included because their ESAs were either aged over 24 (one centre of aeronautics) or under 16 (one centre of gymnastics, one centre of tennis, two centres of basketball).
The remaining 40 centres gathered 616 ESAs aged 16-24 in 30 different sports. Between February and May 2002, ESAs answered a self-administered questionnaire within a training room, in the presence of a professional investigator trained by the ORS-PACA, who was responsible for presenting the survey to the pupils. In order to ensure confidentiality, anonymous questionnaires were collected directly in a ballot box.

The questionnaire was drawn up by an expert group comprising physicians, sociologists and psychologists. Its final version included 127 items dealing with sociodemographic background, health, sporting activity, lifestyle and opinions toward sport and doping. Items related to drug use were based on existing questionnaires (ESCAPAD and ESPAD surveys, cf. Beck, Legleye \& PerettiWatel 2002b; Hibell et al. 2001).

In order to compare ESAs with other girls and boys of a similar age, we also extracted subsamples corresponding to adolescents living in South-Eastern France from two national surveys focusing on drug use and carried outwith a similar methodology (aself-administered questionnaire anonymously completed in a room and collected bya professional investigator):

- The French part of the school survey ESPAD 1999 (European Survey Project on Alcohol and Other Drugs). For the whole country: $n=12113$, pupils aged 13-25; in the present paper: $n=713$, pupils aged $16-$ 20 and living in South-Eastern France (Beck et al. 2002a).

- ESCAPAD 2000-2001 (health and drug use survey during call-up and preparation for defence: this compulsory call-up has replaced military service. Sessions are organized weekly; each session lasts 1 day and gathers boys and girls at the end of adolescence. Each ESCAPAD survey targets one session, in the whole country.) For the whole country: $n=25697$, adolescents aged 1718 ; in the present paper: $n=1555$, aged $17-18$ and living in South-Eastern France (Beck et al. 2002b).

\section{Statistical analysis}

We systematically separated girls and boys in our analyses. We used $t$-test to compare means and Pearson's $c^{2}$ to test the relationship between two categorical variables. When comparing different surveys, we first standardized data on age (we weighted data to have the same mean age across subsamples for each gender, with ESCAPAD as the reference) and we assumed that corresponding subsamples were independent. When focusing on SEPSA subjects, we also computed six multivariate logistic regression models in order to control confounding factors. We used the stepwise method (entry threshold $P=0.1$, which selected step by step the more significant factors (except for age, which was forced into all models). 
For both genders separately, the dependent variableswere three binary drug use variables:

- Cigarettes: current smokers versus non-smokers. Current smokers were defined as people who smoked cigarettes at the time of this study, at least from time to time. This category includes occasional, daily and heavy (at least 10 cigarettes per day) smokers.

- Alcohol: to drink alcohol at least once per month (occasional use) versus less than once per month.

- Cannabis: to have smoked cannabis at least once during the last 12 months (occasional use) versus no use during the last 12 months.

The same explanatory variables were used for all the models, including age (16-17, 18-20, 21-24 years) that was forced in all models as a control factor, and five characteristics related to sporting activity. One referred to the context of this activity: some ESAs lived in a boarding school, thus spent their nights as well as their days in the sporting centre, together with other ESAs. This context extends adult control on them, but it may also increase peer influence. The four remaining characteristics were related to the content of sporting activity:

- Type of sport. The 30 sports were merged into three exclusive types: team sports (handball, rugby, volleyball), sliding sports (snowboard, skiing, parachuting, sailing, kayak, etc.) and other individual sports (judo, squash, cycling, track and field, gymnastics, etc.).

- Weekly duration of sporting activity. ESAs were asked to declare how many hours they practise sport per week. We defined three modalities: ( $£ 10$ hours, 11-15 hours, $>15$ hours.

- Average duration of training sessions. We divided the number of hours played per week by the number of training sessions per week. We defined two modalities: (£2 hours, >2 hours).

- Competitive level. We distinguished three modalities in descriptive statistics (regional, national, international or olympic levels), but for logistic models they were collapsed into a binary outcome: national or regional versus international (international or olympic).

Odds ratios (OR) were computed from the regression coefficients and their level of statistical significance were computed from the Wald's $c^{2}$. Given the small size of our sample, only one decimal is printed for OR. By definition, they are equal to 1 for reference values. All $P$-values are two-tailed. The entire data analysis was carried out with the SPSS" software.

\section{Data collected}

Among the 616 ESAs targeted by the survey, 147 (23.9\%) were absent (most of them were on a sporting trip or busy with a competition), nine (1.5\%) refused to participate and 460 answered the questionnaire (response rate: $74.4 \%$ ). As two of them completed the questionnaire but did not declared their gender, we finally analysed a sample of 458 ESAs aged 16-24 years.

\section{RESULTS}

\section{Sporting characteristics of ESAs}

Among ESAs, boys were slightly older than girls $(P<0.05)$ (Table 1$)$. Concerning sporting characteristics, girls and boys had very similar profiles, with only a slight difference for the type of sport: boys practised sliding sports more often. Two ESAs out of three declared more than 15 hours of sporting practice per week; one of two went in for competitive sport at national level, and one of three at international or olympic level. Concerning drug use, boys were more prone to use alcohol and cannabis, while smoking prevalences were similar for both sexes.

\section{Comparison between ESAs and subjects from other surveys}

The age range of respondents was wider for the SEPSA survey than for ESPAD and ESCAPAD. Prevalences (standardized on age) were dramatically lower among ESAs, for both genders (Table 2). Concerning cigarettes, current smoking prevalence was twice as high in ESPAD and ESCAPAD subsamples corresponding to South-Eastern France (for girls, respectively, $46.6 \%$ and $50.4 \%$ versus $25.1 \%, P<0.001$; for boys, respectively, $44.5 \%$ and $50.1 \%$ versus $20.5 \%, P<0.001$ ), and this difference increased for daily smoking. For alcohol, this difference was significant for regular use ( $\geq 10$ per month), especially among girls. Finally, cannabis use during the last 12 months was about twice as frequent in ESPAD and ESCAPAD subsamples (for girls, respectively, $32.3 \%$ and $42.3 \%$ versus $18.4 \%, P<0.001$; for boys, respectively, $48.3 \%$ and $49.9 \%$ versus $27.0 \%, P<0.001$ ).

\section{Sporting characteristics and drug use among ESAs}

In our logistic models, the age effect on drug use was not systematic: older ESAs were more prone to drink alcohol at least once per month, current smoking was less frequent among boys aged 16-17 (relation only significant at $P<0.1$ ), using cannabis at least once per year was more frequent among boys aged 18-20 (Table 3). Education in a boarding school was correlated positively with current smoking for girls and boys (respectively: $\mathrm{OR}=3.3$ and 1.8 , only significant at $P<0.1$ for the latter $\mathrm{OR}$ ), and with cannabis use of cannabis for girls only (OR $=4.0$ ), but not with alcohol use.

ESAs practising a team sport were more likely to drink alcohol (for girls and boys: $\mathrm{OR}=2.7$ and 1.8, respectively, ORs only significant at $P<0.1$ ) and sliding sports were 
Table I Demographic and sporting characteristics of the SEPSA subjects.

\begin{tabular}{|c|c|c|c|}
\hline & $\begin{array}{l}\text { Girls (\%) } \\
\mathrm{n}=159\end{array}$ & $\begin{array}{l}\text { Boys (\%) } \\
n=299\end{array}$ & $\begin{array}{l}\text { Total (\%) } \\
\mathrm{n}=458\end{array}$ \\
\hline \multicolumn{4}{|l|}{ Age } \\
\hline $16-17(n=211)$ & 51.6 & 43.1 & 46.1 \\
\hline $18-20(n=159)$ & 35.8 & 34.1 & 27.7 \\
\hline $21-24(n=88)$ & 12.6 & $22.7 * *$ & 26.2 \\
\hline (mean) & $(18.0)$ & $(18.5)$ & $(18.3)$ \\
\hline \multicolumn{4}{|l|}{ Boarding school } \\
\hline No $(n=254)$ & 52.2 & 57.2 & 55.5 \\
\hline Yes $(n=204)$ & 47.8 & $42.8 \mathrm{NS}$ & 44.5 \\
\hline \multicolumn{4}{|l|}{ Type of sport } \\
\hline Individual sport $(n=224)$ & 52.8 & 46.8 & 48.9 \\
\hline Team sport $(n=12 \mid)$ & 28.3 & 25.4 & 26.4 \\
\hline Sliding sport $(n=1 \mid 3)$ & 18.9 & $27.8^{*}$ & 24.7 \\
\hline \multicolumn{4}{|l|}{ Weekly duration of sporting activity } \\
\hline fl0 hours per week $(n=164)$ & 31.4 & 38.1 & 35.8 \\
\hline $11-15$ hours per week $(n=172)$ & 40.9 & 35.8 & 37.6 \\
\hline$>15$ hours per week $(n=122)$ & 27.7 & 26.I NS & 26.6 \\
\hline (mean) & $(13.8)$ & $(13.3)$ & $(13.5)$ \\
\hline \multicolumn{4}{|l|}{ Average duration of training sessions } \\
\hline$£ 2$ hours per session $(n=297)$ & 66.0 & 64.2 & 64.8 \\
\hline$>2$ hours per session $(n=|6|)$ & 34.0 & $35.8 \mathrm{NS}$ & 35.2 \\
\hline (mean) & $(2.1)$ & $(2.1)$ & $(2.1)$ \\
\hline \multicolumn{4}{|l|}{ Competitive level } \\
\hline Regional $(n=70)$ & 10.7 & 17.7 & 15.3 \\
\hline National $(n=236)$ & 56.0 & 49.2 & 51.5 \\
\hline International, Olympic $(n=152)$ & 33.3 & 33.I NS & 33.2 \\
\hline \multicolumn{4}{|l|}{ Smoking status } \\
\hline Current smokers $(n=105)$ & 24.5 & 22.I NS & 22.9 \\
\hline Daily smokers $(n=47)$ & 10.1 & I0.4 NS & 10.3 \\
\hline Heavy smokers $(n=10)$ & 0.6 & $3.0 \mathrm{NS}$ & 2.2 \\
\hline \multicolumn{4}{|l|}{ Alcohol use } \\
\hline$\geq 1$ per month $(n=316)$ & 62.9 & $72.2^{*}$ & 69.0 \\
\hline$\geq 10$ per month $(n=27)$ & 0.6 & $8.7 * * *$ & 5.9 \\
\hline \multicolumn{4}{|l|}{ Cannabis use } \\
\hline$\geq I$ during the last 12 months $(n=1 \mathrm{II})$ & 18.2 & $27.4^{*}$ & 24.2 \\
\hline
\end{tabular}

NS: non-significant; $* P<0.10 ; * * P<0.05 ; * * *<0.01$, testing the independence hypothesis between gender and each row variable.

associated positively with cannabis use among girls $(\mathrm{OR}=2.8)$ and with alcohol use among boys $(\mathrm{OR}=4.3)$. For girls, the weekly duration of sporting activity was correlated negatively with current smoking $(\mathrm{OR}=0.3)$ and drinking alcohol $(\mathrm{OR}=0.4$, only significant at $P<0.1$ ), and those who entered competition at international level were more likely to smoke cigarettes and cannabis $(\mathrm{OR}=6.1$ and 2.4 , respectively, only significant at $P<0.1$ for the latter OR). Finally, current smoking was associated positively with longer training sessions among boys $(\mathrm{OR}=2.2)$.

\section{DISCUSSION}

To our knowledge, the SEPSA survey was one of the first conducted on a population of young elite athletes, with a sample size allowing some significant statistical analyses. Before discussing our results, however, two main limitations of our study must be acknowledged. First, even if previous works showed that the South-Eastern France was similar to other French regions for cigarette, alcohol and cannabis use at adolescence (Beck et al. 2002b; Peretti-Watel et al. 2003), our data were derived from a regional survey: they must not be considered to represent a sample of the global French ESAs population. Secondly, our comparisons between ESAs and other adolescents were based on statistical tests relying on the hypothesis that SEPSA subjects and subsamples extracted from ESPAD and ESCAPAD data are homogeneous and independent.This hypothesis is questionable: questionnaires, 
Table 2 Cigarette, alcohol and cannabis use: comparison between ESPAD, ESCAPAD and SEPSA subjects (data standardized on age, reference: ESCAPAD).

\begin{tabular}{|c|c|c|c|c|c|c|}
\hline & \multicolumn{3}{|l|}{ Girls } & \multicolumn{3}{|l|}{ Boys } \\
\hline & ESPAD & ESCAPAD & SEPSA & ESPAD & ESCAPAD & SEPSA \\
\hline & 1999 & $2000-01$ & 2002 & 1999 & $2000-01$ & 2002 \\
\hline \multicolumn{7}{|l|}{ South-Eastern France sample } \\
\hline Sample size & 350 & 788 & 159 & 363 & 767 & 299 \\
\hline Age range (years) & $16-20$ & $17-18$ & $16-24$ & $16-20$ & $17-18$ & $16-24$ \\
\hline Average age (years) & 17.8 & 17.8 & 17.8 & 17.7 & 17.7 & 17.7 \\
\hline \multicolumn{7}{|l|}{ Smoking status } \\
\hline Current smokers (\%) & $46.6 * * *$ & $50.4^{* * * *}$ & 25.1 & $44.5^{* * *}$ & $50.1 * * *$ & 20.5 \\
\hline Daily smokers (\%) & $34.0 * * *$ & $40.1 * * *$ & 10.3 & $31.8 * * *$ & $38.6 * * *$ & 9.4 \\
\hline \multicolumn{7}{|l|}{ Alcohol use } \\
\hline$\geq$ I per month (\%) & $68.0 \mathrm{NS}$ & $73.5^{* * *}$ & 62.8 & 70.9 NS & $78.4^{* *}$ & 70.4 \\
\hline$\geq 10$ per month (\%) & $8.2^{* * *}$ & $4.8 * * *$ & 0.6 & $15.9 * * *$ & $15.3 * * *$ & 5.6 \\
\hline \multicolumn{7}{|l|}{ Cannabis use } \\
\hline$\geq I$ during the last 12 months (\%) & $32.3^{* * *}$ & $42.3 * * *$ & 18.4 & $48.3 * * *$ & $49.9 * * *$ & 27.0 \\
\hline
\end{tabular}

NS: non-significant; $* P<0.10 ; * * P<0.05 ; * * * P<0.01$. For boys and for girls and for each drug use, we tested separately ESPAD and ESCAPAD prevalence versus SEPSA prevalence.

Table 3 Age, sporting activity and drug use for girls and boys (logistic regressions).

\begin{tabular}{|c|c|c|c|c|c|c|}
\hline & \multicolumn{6}{|c|}{ Odds ratios $(O R)$} \\
\hline & \multicolumn{2}{|c|}{$\begin{array}{l}\text { Cigarettes } \\
\text { Current smoking }\end{array}$} & \multicolumn{2}{|c|}{$\begin{array}{l}\text { Alcohol } \\
\geq I \text { per month }\end{array}$} & \multicolumn{2}{|c|}{$\begin{array}{l}\text { Cannabis } \\
\geq 1 \text { /last } 12 \text { months }\end{array}$} \\
\hline & Girls & Boys & Girls & Boys & Girls & Boys \\
\hline \multicolumn{7}{|l|}{ Age (years) 16- } \\
\hline 17 (ref.) & 1 & I & 1 & 1 & 1 & 1 \\
\hline $18-20$ & $0.7 \mathrm{NS}$ & $2.0^{*}$ & $4.6 * * *$ & $2.5 * * *$ & $0.7 \mathrm{NS}$ & $1.8 * *$ \\
\hline $21-24$ & $0.8 \mathrm{NS}$ & $2.0^{*}$ & $7.0 * * *$ & $4.1 * * *$ & I.I NS & $0.7 \mathrm{NS}$ \\
\hline \multicolumn{7}{|l|}{ Boarding school } \\
\hline No (ref.) & 1 & I & - & - & I & - \\
\hline Yes & $3.3^{* *}$ & $1.8^{*}$ & & & $4.0 * * *$ & \\
\hline \multicolumn{7}{|l|}{ Type of sport } \\
\hline Individual sport (ref.) & - & - & 1 & I & I & - \\
\hline Team sport & & & $2.7^{*}$ & $1.8^{*}$ & $0.4 \mathrm{NS}$ & \\
\hline Sliding sport & & & $1.7 \mathrm{NS}$ & $4.3 * * *$ & $2.8 * *$ & \\
\hline \multicolumn{7}{|l|}{ Weekly duration of sporting activity } \\
\hline fIO hours per week (ref.) II- & I & - & I & - & - & - \\
\hline I5 hours per week & $1.2 \mathrm{NS}$ & & $0.7 \mathrm{NS}$ & & & \\
\hline$\geq 15$ hours per week & $0.3^{* *}$ & & $0.4^{*}$ & & & \\
\hline \multicolumn{7}{|l|}{ Average duration of training sessions } \\
\hline$£ 2$ hours per session (ref.) & - & I & - & - & - & - \\
\hline$>2$ hours per session & & $2.2^{* * *}$ & & & & \\
\hline \multicolumn{7}{|l|}{ Competitive level } \\
\hline Regional or national (ref.) & 1 & - & - & - & I & - \\
\hline International or Olympic & $6.1^{* * *}$ & & & & $2.4^{*}$ & \\
\hline
\end{tabular}

Ref. reference value (by definition, odds ratios are equal to I for reference values). —: variable not selected by the stepwise method. NS: non-significant; $* P<0.10 ; * * P<0.05 ; * * * P<0.01$. 
age ranges and years of data collection were different, and overlaps between samples were possible (some SEPSA subjects could have been also included in the two other surveys). However, such overlaps were probably rare, because sampling rates for ESPAD and ESCAPAD were low $(<1 \%)$. Moreover, prevalence differences between ESAs and other surveys' subjects were so considerable that they could not result from uncontrolled statistical biases due to the heterogeneity of our data.

Prevalences turned out to be markedly lower among ESAs. Sporting activity as an elite student-athlete can therefore be considered to be associated negatively with drug use. Nevertheless, this statement must be qualified. First, according to our results it is valid for recreational drugs such as cigarettes, alcohol and cannabis, but we did not study drugs used to enhance sporting performance. Secondly, this protective effect could be only seasonal: elite athletes could reduce their drug use during the competitive season, while consuming just as much as other adolescents during the rest of the year (Bower \& Martin 1999). Unfortunately, our survey was not designed to test this hypothesis. Finally, what is true for young elite athletes could be wrong for the older ones: elite athletes could be 'at risk' for drug use when they break with their sporting carrier (Lowenstein et al. 2000).

A topic which deserves further study is the absence of a clear age effect. This effect is usually very strong at adolescence, for both sexes and any drug use, but as most epidemiological surveys deal with high school or college students, we have little information about what happens during early adulthood. This period is a critical one, between the exploring age of adolescence and the age of choices and renouncing. According to our data, the age effect changes during the transition from adolescence to early adulthood: for occasional use of alcohol it remained strong; for cigarettes it faded (for girls) or levelled-off at 18-20 (for boys); for cannabis it faded (for girls) or was reversed after 18-20 (for boys). The age effect observed for alcohol is due probably to the low consumption threshold (at least once per month): adults are more prone to drink small amounts regularly, while adolescents are characterized by episodic binge drinking (Legleye et al. 2001).

Concerning education in boarding schools, our findings were also unexpected. Such an education extends adult control on adolescents (in general, pupils are less autonomous because they have difficulty in managing separately the different spheres of their life, Goffman 1961), but it may increase peer influence at the same time, so it could be linked either negatively or positively to drug use. We found two strong positive links for girls (for cigarettes and cannabis), and one weaker for boys (for cigarettes). If confirmed by further studies, this difference remains to be explained (perhaps peer influence on drug use applies earlier among boys and becomes less significant at the end of adolescence).

With regard to sporting activity, adolescents practising a team sport were more prone to drink alcohol at least once a month. This threshold is poorly discriminating, but previous studies found the same relationship for higher levels of alcohol use (Peretti-Watel et al. 2002). Practising a sliding sport was also associated strongly with an occasional use of alcohol among boys (at least once a month) and of cannabis among girls (at least once a year). This sexual differentiation needs confirmation in a larger sample, and remains to be interpreted. The relationship between sliding sports and drug use should be interpreted cautiously, because sliding sports and drug use are not necessarily linked by a causal relationship. They can be two ways to meet the same need: 'sensation seeking'. Indeed, according to psychologists this trait of personality is expressed through many behaviours, including 'X-treme' sports (which are often sliding sports) and drug use (Zuckerman 1994). Thus, it is more accurate to conclude that sensation seeking is associated both with drug use and sliding sports (Cherpitel, Meyers \& Perrine 1998; Pillard et al. 2001) rather than considering that sliding sports are the cause of drug use.

A last topic that must be underlined is the finding that girls competing at international level were more likely to smoke cigarettes and cannabis. Because using tobacco to manage stress seems more frequent among women (Sorensen \& Pechacek 1987; Waldron 1991), this finding illustrates the fact that tobacco and cannabis can be used in order to alleviate competitive stress and anxiety, which are frequent among young athletes (Passer 1983; Smoll \& Smith 1990; Bray et al.2000). As we compared levels of use of elite athletes and other adolescents, but not motives to use, this finding also emphasizes the need to improve our understanding of the specific motives for drug use among athletes.

\section{ACKNOWLEDGEMENTS}

This study was supported by the Regional Council of South-Eastern France (Provence, the Alps and the French Riviera) and the Regional and Departmental Authority on Youth and Sports of South-Eastern France (DRDJS PACA). Special thanks to: the presidents of the sporting leagues of PACA; the directors of the CREPS PACA; the officials, the coach and of course the ESAs of the sporting public centres who participated to the survey.

\section{REFERENCES}

Beck, F., Legleye, S. \& Peretti-Watel, P. (2002a) Alcohol, Cigarette, Cannabis and Other Illicit Drugs Among High-school Students, ESPAD 99. France: Tome II. 
Beck, F., Legleye, S. \& Peretti-Watel, P. (2002b) Health, Life-style and Drug Use at 18, ESCAPAD 2001 Survey. Paris: rapport OFDT.

Bower, B. L. \& Martin, M. (1999) African American female basketball players: an examination of alcohol and drug behaviors. Journal of American College Health, 48, 129-133.

Bray, S. R., Martin, K. A. \& Widmeyer, W. N. (2000) The relationship between evaluative concerns and sport competition state anxiety among youth skiers. Journal of Sport Sciences, 18, 353-361.

Challier, B., Chau, N., Predine, R., Choquet, M. \& Legras, B. (2000) Associations of family environment and individual factors with tobacco, alcohol, and illicit drug use in adolescents. European Journal of Epidemiology, 16, 33-42.

Cherpitel, C. J., Meyers, A. R. \& Perrine, M. W. (1998) Alcohol consumption, sensation seeking and ski injury: a case-control study. Journal of Studies on Alcohol, 59, 216-221.

Choquet, M. \& Arvers, P. (2002) Beyond the U-curve: a reply to Peretti-Watel et al. Addiction, 97, 1607-1608.

Forman, E. S., Dekker, A. H., Javors, J. R. \& Davison, D. T. (1995) High-risk behaviors in teenage male athletes. Clinical Journal of Sport Medicine, 5, 36-42.

Goffman, E. (1961) Asylums: Essays on the Social Situation of Mental Patients and Other Inmates. New York: Doubleday Anchor.

Green, G. A., Uryasz, F. D., Petr, T. A. \& Bray, C. D. (2001) NCAA study of substance use and abuse habits of college studentathletes. Clinical Journal of Sport Medicine, 11, 51-56.

Hellandsjo-Bu, E. T., Watten, R. G., Foxcroft, D. R., Ingebrigtsen, J. E. \& Relling, G. (2002) Teenage alcohol and intoxication debut: the impact of family socialization factors, living area and participation in organized sports. Alcohol and Alcoholism, 37, 74-80.

Hibell, B., Andersson, B., Ahlstrom, S., Balakireva, O., Bjarnarsson, T., Kokkevi, A. \& Morgan, M. (2001) Alcohol and Other Drug Use Among Students in 30 European Countries. The 1999 ESPAD Report. Stockholm: Swedish Council for Information on Alcohol and Other Drugs (CAN).

Kokotailo, P. K., Henry, B. C., Koscik, R. E., Fleming, M. F. \& Landry, G. L. (1996) Substance use and other health risk behaviors in collegiate athletes. Clinical Journal of Sport Medicine, 6, 183-189.

Legleye, S., Ménard, C., Baudier, F. \& Le Nezet, O. (2001) Alcool. In: Guilbert, P., Baudier, F. \& Gautier, A., eds. Baromètre Santé 2000, Résultats, pp. 123-159. Vanves: French Board for Health Education (CFES).

Lorente, F. (2002) Sports involvement can be both formal and informal at the same time: a comment on Peretti-Watel et al. Addiction, 97, 1609.

Lowenstein, W., Arvers, P., Gourarier, L., Porche, A. S., Cohen, J. M., Nordmann, F., Prevot, B., Carrier, C. \& Sanchez, M. (2000) Physical and sports activities in the history of patients treated for addictions. Report 1999 of the study sponsored by the Ministry of Youth and Sports (France). Annales de Médecine Interne, 151, A18-A26.

McArdle, P., Wiegersma, A., Gilvarry, E., McCarthy, S., Fitzgerald, M., Kolte, B., Brinkley, A., Blom, M., Stoeckel, I., Pierolini,
A., Michels, I., Johnson, R. \& Quensel, S. (2000) International variations in youth drug use: the effect of individual behaviours, peer and family influences, and geographical location. European Addiction Research, 6, 161-162.

Naylor, A. H., Gardner, D. \& Zaichkowsky, L. (2001) Drug use patterns among high school athletes and nonathletes. Adolescence, 36, 627-639.

Passer, M. W. (1983) Fear of failure, fear of evaluation, perceived competence, and self-esteem in competitive-trait-anxious children. Journal of Sport Psychology, 5, 172-188.

Pate, R. R., Trost, S. G., Levin, S. \& Dowda, M. (2000) Sports participation and health-related behaviors among US youth. Archives of Pediatrics and Adolescence Medicine, 154, $904-$ 911.

Peretti-Watel, P., Beck, F. \& Legleye, S. (2002) Beyond the Ucurve: the relationship between sport and alcohol, cigarette and cannabis use in adolescents. Addiction, 97, 707716

Peretti-Watel, P., Beynet, A., Beck, F. \& Legleye, S. (2003) La diffusion géographique des usages de produits psychoactifs à l'adolescence [Geographical diffusion of drug use at adolescence]. Alcoologie et Addictologie, 24, 127-133.

Pillard, F., Cances-Lauwers, V., Godeau, E., Navarro, F., Rolland, Y. \& Riviere, D. (2001) Sport practice and cannabis consumption in a representative sample of French high school adolescents. Annales de Médecine Interne (Paris), 152, 28-36.

Quarrie, K. L., Feehan, M., Waller, A. E., Cooke, K. R., Williams, S. \& McGee, R. (1996) The New Zealand Rugby Injury and Performance Project: alcohol use patterns within a cohort of rugby players. Addiction, 91, 1865-1868.

Rolandsson, M. \& Hugoson, A. (2000) Knowledge and habits of tobacco among ice-hockey-playing boys. An intervention study. Swedish Dental Journal, 24, 59-70.

Smoll, F. L. \& Smith, R. E. (1990) Psychology of the young athlete, stress-related maladies and remedial approaches. Sports Medicine, 37, 1021-1046.

Sorensen, G. \& Pechacek, T. F. (1987) Attitudes toward smoking cessation among men and women. Journal of Behavioral Medicine, 10, 129-137.

Thombs, D. L. (2000) A test of the perceived norms model to explain drinking patterns among university student athletes. Journal of American College Health, 49, 75-83.

Waldron, I. (1991) Patterns and causes of gender differences in smoking. Social Science and Medicine, 32, 989-1005.

Walsh, M. M., Ellison, J., Hilton, J. F., Chesney, M. \& Ernster, V. L. (2000) Spit (smokeless) tobacco use by high school baseball athletes in California. Tobacco Control, 9, 32-39.

Wechsler, H., Davenport, A. E., Dowdall, G. W., Grossman, S. J. \& Zanakos, S. I. (1997) Binge drinking, tobacco, and illicit drug use and involvement in college athletics. A survey of students at 140 American colleges. Journal of American College Health, 45, 195-200.

Zuckerman, M. (1994) Behavioural Expressions and Biosocial Bases of Sensation Seeking. Cambridge: Cambridge University Press. 
Appendix Age, sporting activity and drug use for girls and boys (numbers of observations).

\begin{tabular}{|c|c|c|c|c|c|c|}
\hline & \multicolumn{2}{|c|}{$\begin{array}{l}\text { Cigarettes } \\
\text { Current smoking }\end{array}$} & \multicolumn{2}{|c|}{$\begin{array}{l}\text { Alcohol } \\
\geq I \text { per month }\end{array}$} & \multicolumn{2}{|c|}{$\begin{array}{l}\text { Cannabis } \\
\geq 1 \text { /last I } 2 \text { months }\end{array}$} \\
\hline & Girls & Boys & Girls & Boys & Girls & Boys \\
\hline \multicolumn{7}{|l|}{ Age (years) } \\
\hline $16-17$ & 23 & 22 & 44 & 83 & 17 & 32 \\
\hline $18-20$ & 12 & 27 & 40 & 78 & 8 & 37 \\
\hline $21-24$ & 4 & 17 & 16 & 55 & 4 & 13 \\
\hline \multicolumn{7}{|l|}{ Boarding school } \\
\hline No & 14 & 33 & 52 & 123 & 10 & 40 \\
\hline Yes & 25 & 33 & 48 & 93 & 19 & 42 \\
\hline \multicolumn{7}{|l|}{ Type of sport } \\
\hline Individual sport & 16 & 25 & 52 & 93 & 15 & 38 \\
\hline Team sport & 12 & 18 & 27 & 51 & 5 & 22 \\
\hline Sliding sport & 11 & 23 & 21 & 72 & 9 & 22 \\
\hline \multicolumn{7}{|c|}{ Weekly duration of sporting activity } \\
\hline flO hours per week & 13 & 22 & 27 & 86 & 9 & 34 \\
\hline II-15 hours per week & 19 & 24 & 43 & 76 & 11 & 26 \\
\hline$<15$ hours per week & 7 & 20 & 30 & 54 & 9 & 22 \\
\hline \multicolumn{7}{|c|}{ Average duration of training sessions } \\
\hline$£ 2$ hours per session & 26 & 34 & 62 & 140 & 18 & 52 \\
\hline$>2$ hours per session & 13 & 32 & 38 & 76 & I & 30 \\
\hline \multicolumn{7}{|l|}{ Competitive level } \\
\hline Regional or national & 19 & 43 & 63 & 139 & 15 & 58 \\
\hline International or Olympic & 20 & 23 & 37 & 77 & 14 & 24 \\
\hline
\end{tabular}


